\title{
Comparative Study on Nigerian Wild and Edible Beans in Reversing Incidence of Colon Cancer in Albino Rats
}

\author{
0. A. Awoyinka1, A. Ileola'2, C. N. Imeoria ${ }^{3}$, A. E. Omonisi', F. C. Oladele1, M. F. Asaolu² \\ ${ }^{1}$ Department of Medical Biochemistry, College of Medicine, Ekiti State University, Ado Ekiti, Nigeria \\ ${ }^{2}$ Department of Biochemistry, Ekiti State University, Ado Ekiti, Nigeria \\ ${ }^{3}$ Department of Science Laboratory Technology, Ekiti State University, Ado Ekiti, Nigeria \\ ${ }^{4}$ Department of Anatomic Pathology, College of Medicine, Ekiti State University, Ado Ekiti, Nigeria \\ Email: olayinka.awoyinka@eksu.edu.ng
}

Received 4 May 2016; accepted 8 July 2016; published 11 July 2016

Copyright (C) 2016 by authors and OALib.

This work is licensed under the Creative Commons Attribution International License (CC BY).

http://creativecommons.org/licenses/by/4.0/

(c) (i) Open Access

\begin{abstract}
This work is an investigation of the curative effects of some edible and wild type beans on colonic inflammation induced by Dextran Sulphate Sodium (DSS) in wister albino rats. Macroscopic examination performed on the colon after seven-day exposure of the animals to both DSS and bean sample revealed a high incidence of colonic inflammation in rats fed with macuna compared to other groups. However, from the histological examination, the groups fed with Otili and Feregede had a low incidence of dysplasia showing Otili and Feregede to be good candidates that could mitigate effect of Dextran Sodium Sulphate.
\end{abstract}

\section{Keywords}

Dextran Sodium Sulphate (DSS) Otili, Feregede, Pakala, Mucuna, Colon Cancer

Subject Areas: Biochemistry

\section{Introduction}

Diets are known to play a major role in the development of many non-communicable diseases such as colon cancer. Thus, dietary compounds are of special relevance for improving the body's defenses against such diseases. Information about the role of diet has come from many observational studies around the world across cultures and geographical divides [1] [2]. Foods such as beans are rich in carbohydrate, low in fat and contain large amount of fibre which help attract water to the stool and enhance transit time of waste through the colon [3] [4]. This may help to combat constipation, colon cancer, and other conditions that afflict the digestive tract. De- 
spite the strong relationship of dietary habits to risk of colorectal cancer (CRC), epidemiologic studies are generally insufficient to conclude dry beans decrease CRC risk, although there are some suggestions of a protective effect [5]-[8].

In general, the current treatment options for colorectal cancer are surgery, chemotherapy, and biological therapies. The majority of patients with early-stage colorectal cancer will undergo surgery to remove as much of the tumor as possible [9]-[17]. Many people with colorectal cancer initially respond to chemotherapy, but unfortunately, in the majority of cases the disease eventually progresses after first-line treatment. Several types of biological therapy are available to treat metastatic colorectal cancer including anti-angiogenics and the Epidermal Growth Factor Receptor (EGFR) inhibitors. Most often they are given in combination with chemotherapy [10]. Radiotherapy is not often used to treat metastatic colorectal cancer due to side effects, although it can be used after surgery to destroy any residual cancer cells [11].

Cost effectiveness analyses of the many interventions (primary prevention, screening or treatment) for reducing the burden of colorectal cancer have usually been restricted to developed country settings and with often considerable variation in the analytical methods used. This limits the value of the existing literature to inform colorectal cancer control policies in low to middle income country settings such as Nigeria. Assessment of costs and effects of different strategies can help guide decisions on the allocation of resources across interventions, as well as between interventions for colorectal cancer. Hence the aim of this present work is to know if the local unexploited wild beans would reverse incidence of colon cancer induced by Dextran Sodium Sulphate (DSS) in wister albino rats and compare the effect with common edible beans.

\section{Materials and Method}

\section{Collection of Cultivar}

Dry, wild bean-Sphenostyles stenocarpa (Otili), Cajanus cajan (Feregede), Phaseolus lunatus (Pakala), were sourced from the bush of Ado Ekiti environ while the wild type-Mucuna cochindunum (Mucuna), and edible type bean-Phaseolus vulgaris tagged, IT845-2246-4 were brought from International Institute of Tropical Agriculture (IITA), Ibadan Nigeria. They were collected whole, dry and naked (i.e. without pods), with divers colors (off white, gold, navy blue, black and brown respectively). Authentication was carried at the herbarium of the Plant Science Department, Ekiti State University Ado Ekiti before the dried seeds were pulverised.

\section{Experimental Animals}

Sixteen male and twelve female albino rats were used in this study. Their weights ranged between $60 \mathrm{~g}$ to 100 grams. The rats were fed ad-libitum with pulverized bean samples and $5 \mathrm{mg} / \mathrm{Kg}$ of Dextran Sodium Sulphate (DSS) dissolved in water for seven days to induce colonic inflammation. An average of $15 \mathrm{~mL}$ of the DSS-water was given to the singly caged rat under group A-E daily. They are Otili, Feregede, Pakala, Mucuna and edible bean cultivar IT845-2246-4 groups respectively. However the Control Group was fed with rat chow and $15 \mathrm{~mL}$ of $5 \mathrm{mg} / \mathrm{Kg}$ body weight DSS treated water, while the Basal group was fed with rat chow and normal saline daily.

\subsection{Macroscopic Examination}

The method of Thaker, et al., [12] was adopted. The mouse with its ventral side exposed on a cutting board. 70\% ethanol was used to cover the abdomen to prevent hairs from contaminating the abdominal contents during extraction of the colon. Scissors was used to cut through the pelvis so that the colon can be harvested down to the anorectal junction. The flushed colon was placed in phosphate-buffered saline (PBS) in order to maintain the physiologic condition before the macroscopic analysis. However 1\% Alcian blue dye was applied to the highlighted tumors when Digital photography was taken in a dark fixated length by Nikon Camera. Tumor burden (\%) was calculated as tumor area/total colon area using Image J software [13].

\subsection{Histological Examinations}

Prior to photomicrograph, small pieces of colon sections were fixed in $10 \%$ formalin saline, after which they were cut and stained with haematoxylin and eosin. The stained tissue sections were then observed under a light 
microscope (Olympus 400× objective) for histological assessment.

\section{Results and Discussion}

Experimental studies have been conducted specifically examining the relationship of dry bean consumption to chemically-induced colon cancer in rats. For instance, Hughes et al., [14] fed rats diets containing either pinto beans $(59 \% \mathrm{wt} / \mathrm{wt})$ or casein as the protein source. They found that feeding pinto beans inhibited colon tumor incidence by $52 \%$ (50\% in casein-fed animals vs. $24 \%$ in bean-fed animals) and significantly reduced the number of tumors that developed ( $1.0 \pm 0.0$ vs. $2.5 \pm 0.6$ tumors/ tumor bearing animal). In a similar design, Hangen and Bennink [15] also reported a protective effect of dry beans on experimental colon cancer. They found that feeding either black beans or navy beans ( $75 \% \mathrm{wt} / \mathrm{wt}$ ) inhibited colon cancer by $~ 57 \%$, and similar to Hughes et al., [14], bean-fed rats also developed fewer tumors (1.0 \pm 0.17 vs. $2.2 \pm 1.2$ tumors/tumor bearing animal). It was on this premise that this present work was set out following the Morton and Griffiths [16] groundwork laid for developing a set of observations for assessing behavioral and physiological changes in laboratory animals.

Significant changes were observed in all physiological categories but observation recorded in day 1 was insignificant in day 1 . As shown in Figure 1 responses to the amount of food consumed by each rat group were encouraging except in group fed with mucuna. The group fed with mucuna experienced a notable reduction in weight just at day 2 . This reduction definitely was induced by a loss of appetite and a reduction in food and water-treatment consumed (Figure 1). While feregede group experienced a slight reduction in weight and heart beat rate although it remained active all day round. Pakala and feregede groups had similar effects with a slight decrease in weight and food consumed while group fed with common edible bean had no noticeable weight

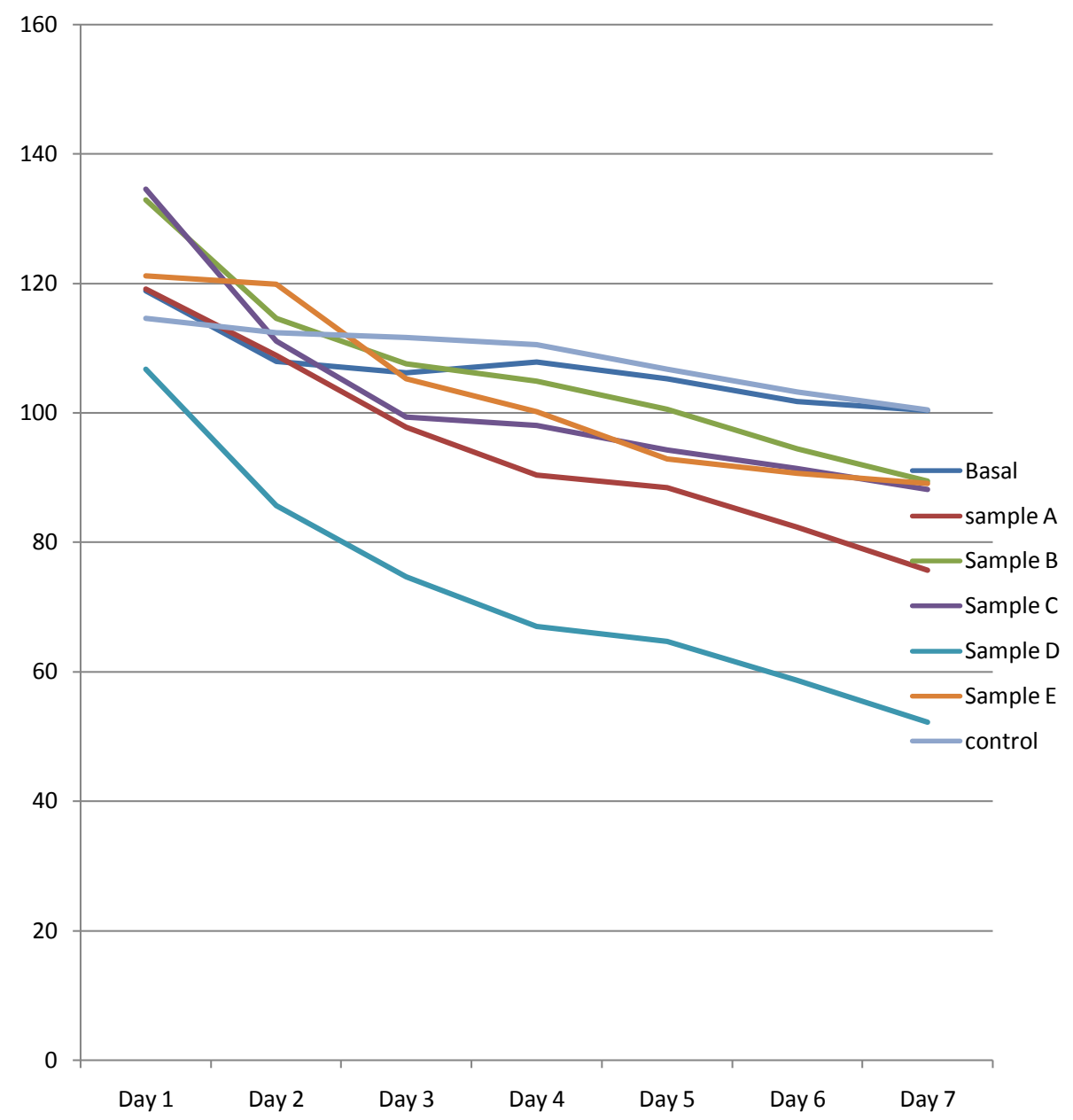

Figure 1. Standard curves showing daily weight of rats. 
change between day 1 and 2, but experienced a slight decrease in weight on the $5^{\text {th }}$ day of the experiment (Figure 2) At day 4 group fed with Otili experienced a sharp reduction in weight on the fourth day of the experiment this was maintained over the fifth day before decreasing to 75.7 on day 7 of the experiment. This depreciation in weight is also relative to low amount of food consumed at this period.

Macroscopic result (Table 1) before sacrifice on seventh day shows that control had the highest \% tumor burden of $64.9 \%$ and Otili group had the lowest with $14.3 \%$ along with B with $15 \%$. Pakala group had a relatively high percent of $60.3 \%$, preceded by group fe with common edible bean with $58.4 \%$ tumor burden. Death was recorded for mucuna group before the seventh day so this measurement was not ascertained for them. Further histological assessment showed dyspepsia observed on the control group (Picture 1). Though the dyspepsia was mild in the Otili group (Picture 2), while that of feregede group was also moderate (Picture 3), however dyspepsia in group fed with pakala (Picture 4) appeared more severe compared to otili, feregede and edible bean IT845-2246-4 (Picture 5). Maximum effect of the DSS was found to be in the Mucuna group with profound lesions showing on the tissues (Picture 6).

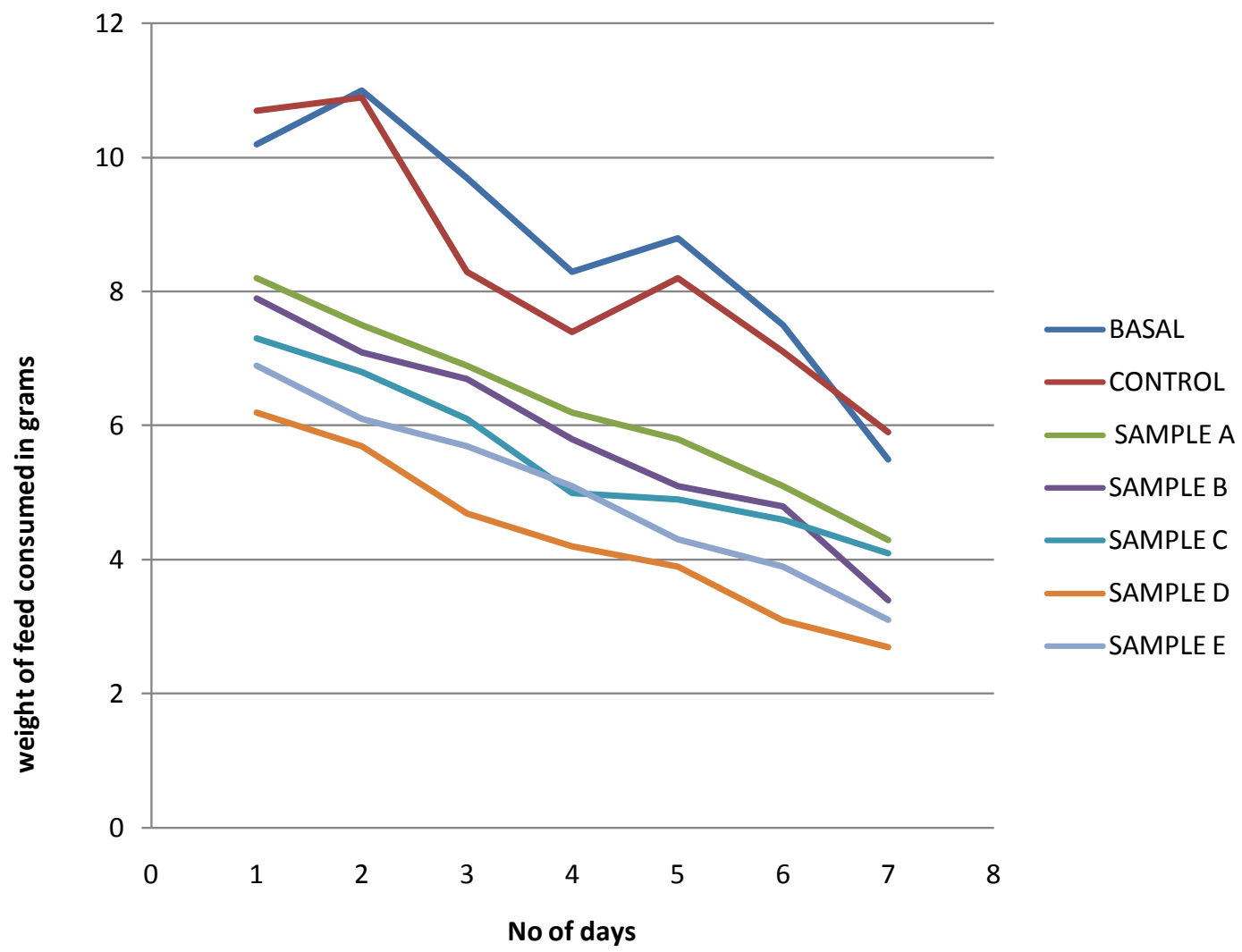

Figure 2. Graph of weight of daily food consumed.

Table 1. Macroscopic assessment of \%tumor burden.

\begin{tabular}{cc}
\hline Group & \% Tumor Burden \\
\hline Control & 64.9 \\
A & 14.3 \\
B & 15 \\
C & 60.3 \\
D & N/A \\
E & 58.4 \\
\hline
\end{tabular}




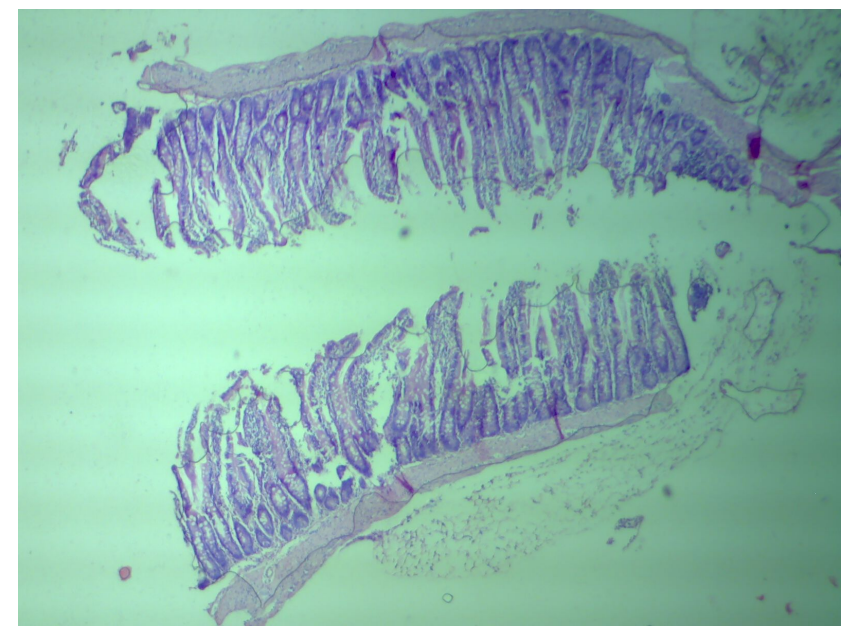

Picture 1. Result of histological examination of control group wistar rats.

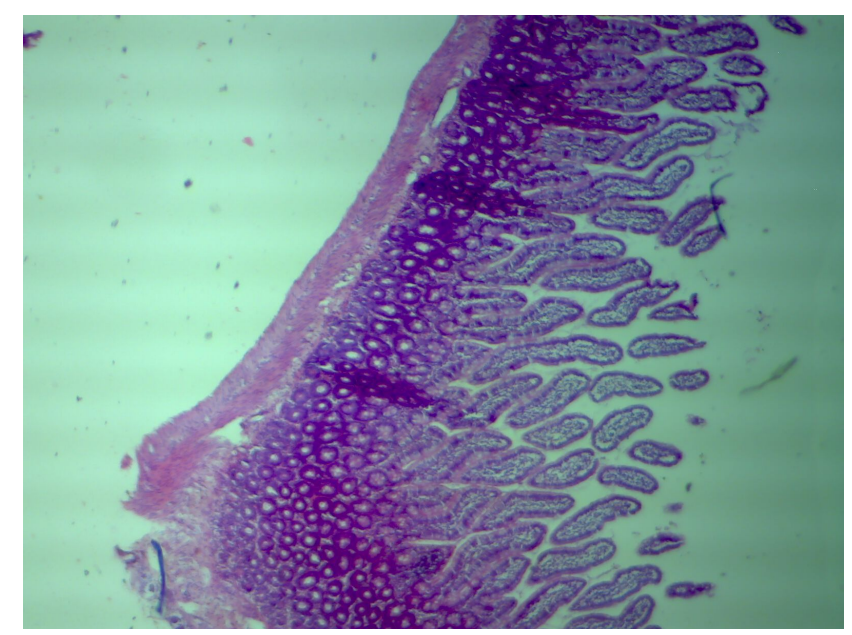

Picture 2. Result of histological examination of rats fed with Otili.

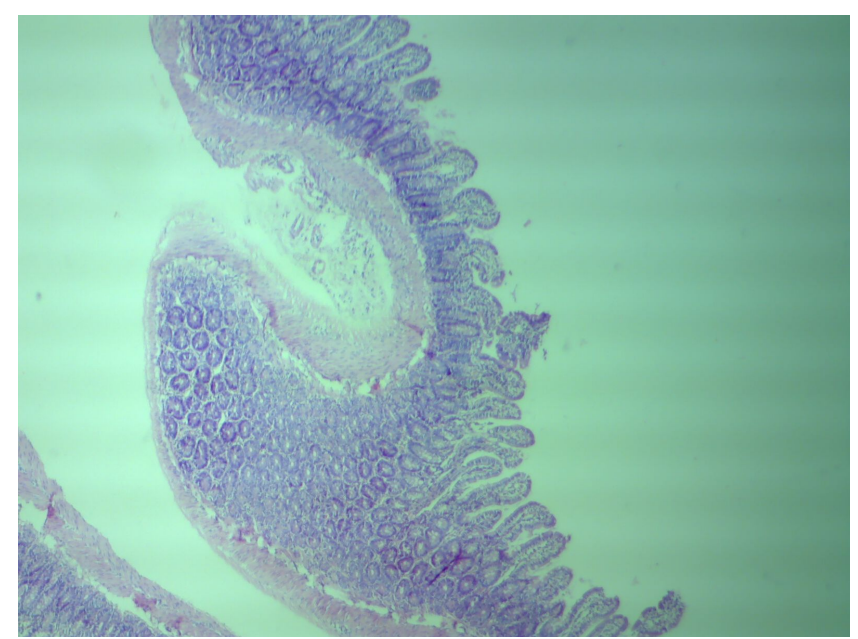

Picture 3. Result of histological examination of rats fed with $\mathrm{fe}$ regede. 


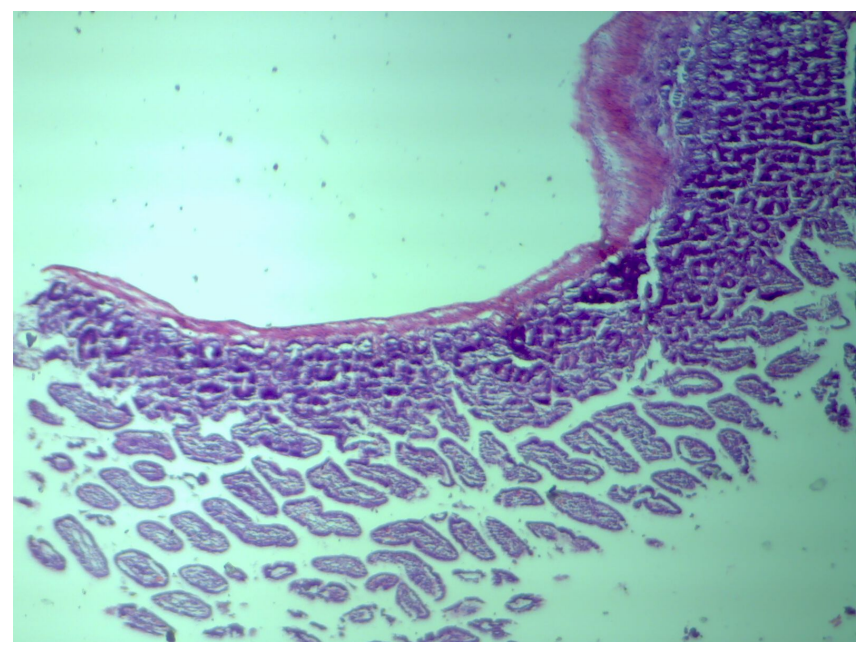

Picture 4. Result of histological examination of rats fed with pakala.

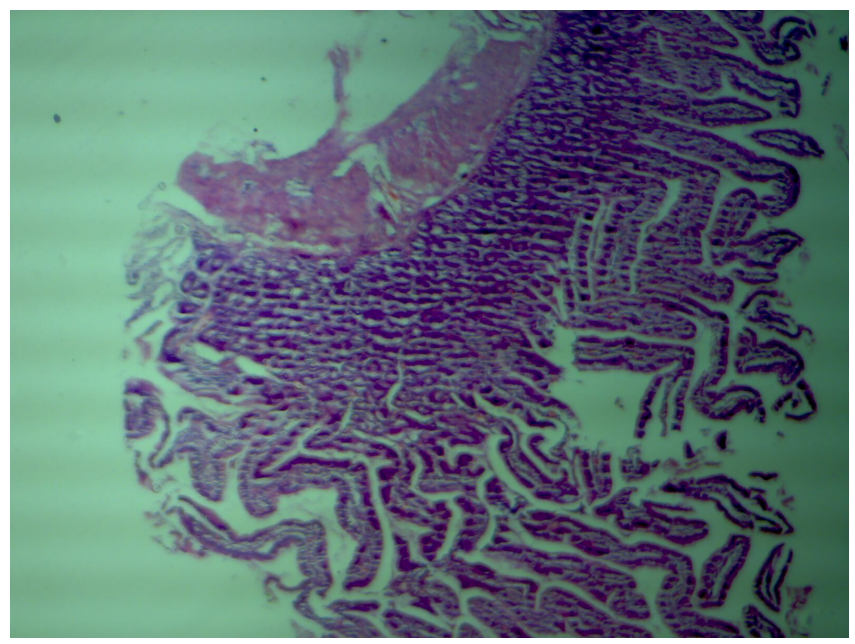

Picture 5. Result of histological examination of group E rats.

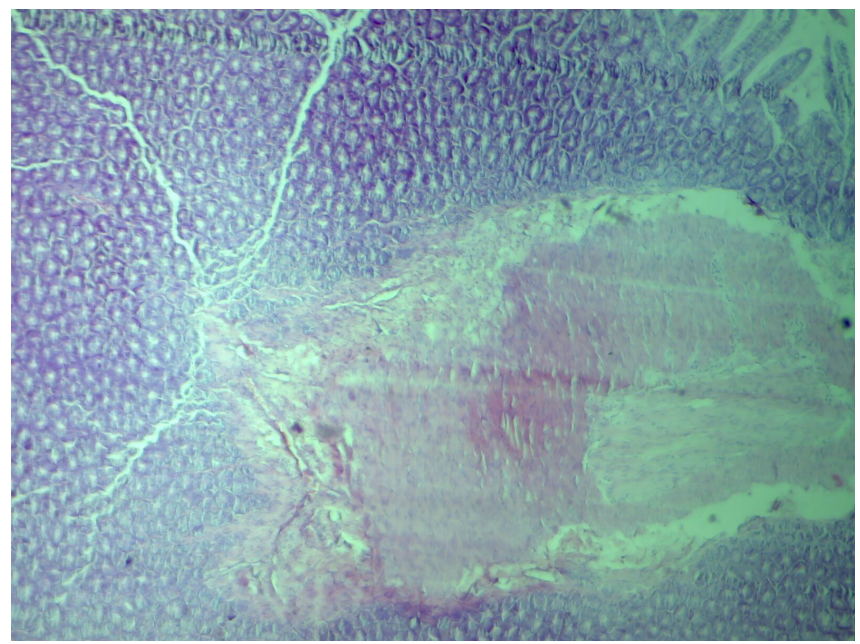

Picture 6. Result of histological examination ofrats fed with $m u$ cuna. 


\section{Conclusion}

In this present study, it is justifiable to say that group of rats fed with Mucuna had the least enduring ability to the DSS treatment being induced into it. Rats fed with Otili and Feregede expressed higher resistibility ability to the proliferation of cancer cells.

\section{Acknowledgements}

The present project was partly funded by Tet Fund Individual Based Research grant 2015-2016 session.

\section{References}

[1] Vucenik, I. and Shamsuddin, A.M. (2006) Protection against Cancer by Dietary IP6 and Inositol. Nutrition and Cancer, 55, 109-125. http://dx.doi.org/10.1207/s15327914nc5502 1

[2] Winham, D., Webb, D. and Barr, A. (2008) Beans and Good Health. Nutrition Today, 5, 201-208. http://dx.doi.org/10.1097/01.NT.0000303354.21347.45

[3] De Mejia, E., Guzman-Maldonado, S.H., Acosta-Gallegos, J.A., Reynoso-Camacho, R., Ramirez-Rodriguez, E., PonsHernandez, J.L., Gonzalez-Chavira, M.M., Castellanos, J.Z. and Nelly, J.D. (2003) Effect of Cultivar and Growing Location on the Trypsin Inhibitors, Tannins and Lectins of Common Beans (Phaseolus vulgaris L.) Grown in Semiarid Highlands of Mexico. Journal of Agricultural and Food Chemistry, 51, 5962-5966. http://dx.doi.org/10.1021/jf030046m

[4] Oseguera-Toledo, M.E., de Mejia, E.G., Dia, V.P. and Amaya-Llano, S.L. (2011) Common Bean (Phaseolus vulgaris L.) Hydrolysates Inhibit Inflammation in LPS-Induced Macrophages through Suppression of NF- $\kappa$ B Pathways. Food Chemistry, 127, 1175-1185. http://dx.doi.org/10.1016/j.foodchem.2011.01.121

[5] Geil, P.B. and Anderson, J.W. (1994) Nutrition and Health Implications of Dry Beans: A Review. American College of Nutrition, 13, 549-558. http://dx.doi.org/10.1080/07315724.1994.10718446

[6] Koratkar, R. and Rao, A.V. (1997) Effect of Soybean Saponins on Azoxymethane-Induced Prneoplastic Lesions in the Colon of Mice. Nutrition and Cancer, 27, 206-209. http://dx.doi.org/10.1080/01635589709514526

[7] Schatzkin, A., Mouw, T., Park, Y., Subar, A.F., Kipnis, V., Hollenbeck, A., Leitzmann, M.F. and Thompson, F.E. (2007) Dietary Fiber and Whole-Grain Consumption in Relation to Colorectal Cancer. The American Journal of Clinical Nutrition, 85, 1353-1360.

[8] Del Rio, D., Rodriguez-Mateos, A., Spencer, J.P.E., Tognolini, M., Borges, G. and Crozier, A. (2012) Dietary Polyphenolics in Human Health: Structures, Bioavailability, and Evidence of Protective Effects against Chronic Diseases. Antioxidants \& Redox Signaling, 12, 5-6.

[9] Labianca, R. (2010) Primary Colon Cancer: ESMO Clinical Practice Guidelines for Diagnosis, Adjuvant Treatment and Follow-Up. Annals of Oncology, 21, v70-v77. http://dx.doi.org/10.1093/annonc/mdq168

[10] John, S.K.P., George, S., Primrose, J.N. and Fozard, J.B.J. (2011) Symptoms and Signs in Patients with Colorectal Cancer. Colorectal Disease, 13, 17-25. http://dx.doi.org/10.1111/j.1463-1318.2010.02221.x

[11] NCCN (2011) National Comprehensive Cancer Network on Clinical Practice Guidelines in Oncology: Colon.

[12] Thaker, A.I., Shaker, A., Rao, M.S. and Ciorba, M.A. (2012) Modeling Colitis-Associated Cancer with Azoxymethane (AOM) and Dextran Sulfate Sodium (DSS). Journal of Visualized Experiments, 67, e4100. http://dx.doi.org/10.3791/4100

[13] Collins, T.J. (2007) Image J for Microscopy. BioTechniques, 43, S25-S30. http://dx.doi.org/10.2144/000112517

[14] Hughes, J.S., Ganthavorn, C. and Wilson-Sanders, S. (1997) Dry Beans Inhibit Azixymethane-Induced Colon Carcinogenesis in F344 Rats. Journal of Nutrition, 127, 2328-2333.

[15] Hangen, L. and Bennink, M.R. (2002) Consumption of Black Beans and Navy Beans (Phaseolus vulgaris) Reduced Azoxymethane-Induced Colon Cancer in Rats. Nutrition and Cancer, 44, 60-65. http://dx.doi.org/10.1207/S15327914NC441_8

[16] Morton, D.B. and Griffiths, P.H.M. (1985) Guidelines on the Recognition of Pain and Discomfort in Experimental Animals and a Hypothesis for Assessment. Veterinary Record, 116, 431-436. http://dx.doi.org/10.1136/vr.116.16.431

[17] Hennessy, B.T., Coleman, R.L. and Markman, M. (2009) Ovarian Cancer. Lancet, 374, 1371-1382. http://dx.doi.org/10.1016/S0140-6736(09)61338-6 


\section{Warmly welcome your paper submission to OALib Journal!}

- Publication on a daily basis

- 9 subject areas of science, technology and medicine

- Fair and rigorous peer-review system

- Fast publication process

- Article promotion in various social networking sites (LinkedIn, Facebook, Twitter, etc.)

- Widely-targeted and multidisciplinary audience to read your research

Submit Your Paper Online: Click Here to Submit

Contact Us: service@oalib.com 